\title{
Post-surgical outcomes of laparoscopic appendectomy observed at BIRDEM hospital
}

\author{
Tapash Kumar Maitra, Mahmud Ekramullah, Faruquzzaman, Samiran Kumar Mondol \\ Department of Surgery, BIRDEM General Hospital, Dhaka, Bangladesh
}

\begin{abstract}
Background and Objective: Currently, laparoscopic appendectomy (LA) is widely practiced for the management of acute appendicitis (AA). The application of laparoscopic technique for appendectomy is expanding very rapidly and now performed in almost all major cities and tertiary level hospitals. This study addressed to determine the outcomes of laparoscopic appendectomy in our surgical setup at Bangladesh Institute of Research and Rehabilitation in Diabetes, Endocrine and Metabolic Disorder (BIRDEM).
\end{abstract}

Methodology: All admitted patients at BIRDEM hospital and clinically diagnosed as acute appendicitis considered eligible for the study. Based on clinical history relevant and routine biochemical investigations were done. A board of experienced surgeons selected the eligible cases for LA. The study continued from Sept 2014 to Sept 2016.

Result: A total of $47(\mathrm{M} / \mathrm{F}=21 / 26)$ patients with acute appendicitis were admitted during this period. The mean (SD) age was $21( \pm 1.4)$ years in male and $19( \pm 1.7)$ years in female. The mean age of the total patients was $20( \pm 1.6)$ years. Eighty percent of the patients were of age 30 years or less. Per-operative laparoscopic findings revealed that five cases $(10.6 \%)$ were misdiagnosed as appendicitis. Two (4.2\%) cases were found to have other pathology and necessitated open appendectomy (OA). One was suspected for malignancy and other had appendicitis with adhesion. Overall, four important post-operative outcomes were observed: (a) post-operative pain was found reducing gradually and it fell below pain score 2 or even less after 30 hours; (b) port-site bleeding and infection were observed in $4.3 \%$ and $2.1 \%$, respectively; (c) none had visceral bleeding or subcutaneous emphysema and (d) more than $80 \%$ were discharged within 72 hours.

Conclusion: Most of the patients admitted with acute appendicitis were of younger age $(<30$ years). Though there was no comparative group undergoing open appendectomy (OA), it was apparent that laparoscopic approach was proved to have reduced pain, less complication and shorter hospital stay thus reducing the treatment cost. Thus, LA was found relatively safe and resilient procedure. An additional benefit of laparoscopy was that it revealed about $10 \%$ case were misdiagnosed as having appendicitis. Thus, this approach may be considered as a step forward in the treatment of appendicitis making easier to explore the abdominal cavity while keeping an option to perform an OA.

IMC J Med Sci 2017; 11(1): 15-18

\section{Introduction}

The laparoscopic surgery technique has rapidly spread because of its several advantages over conventional open surgery [1]. The diminishment of postoperative pain and the reduction of length of hospital stay as well as the earlier return to work generated a positive socioeconomic impact $[2,3]$.

Address for Correspondence:

Dr. Tapash Kumar Maitra, Associate Professor \& Head, Department of Surgery, BIRDEM General Hospital, 122 Kazi Nazrul Islam Avenue, Shahbag, Dhaka, Bangladesh.Email: tapashkm1965@gmail.com 
However, despite being minimal invasive this surgical method, postoperative complications and open conversion cannot be disregarded $[4,5]$.

Open appendectomy (OA) has been the gold standard for the treatment of acute appendicitis since its introduction by Charles McBurney in 1894 [6]. Unfortunately, the diagnosis of acute appendicitis is often difficult, mainly clinical and always challenging. An accepted negative appendectomy rate for presumed appendicitis ranges from $15 \%$ to $20 \%$, even higher in women of childbearing age (20\% to $30 \%)[7,8]$.

Laparoscopic appendectomy (LA) has evolved since the first performed by a German Gynecologist Kurt Semm (1983) [9]. Laparoscopic appendectomy has gained acceptance as a diagnostic and treatment method for acute appendicitis with the technological advances of the past two to three decades. Since then, this procedure has been widely used. In spite of its wide acceptance, there remains a continuing controversy in the literature regarding the most appropriate way of removing the inflamed appendix because of a set of new operative complications relating to laparoscopic surgery $[8,9]$. Minimal access surgery has been proved to be a useful surgical technique. The application of the recent technology and skills can now provide a better and a cheaper choice of treatment. Despite a lot of randomized trials which have compared laparoscopic and open appendectomy, the indications for laparoscopy in patients with suspected appendicitis remains controversial and clinical trials comparing LA versus OA, a consensus concerning the relative advantages of each procedure has not yet been reached [10-11].

The present study was designed to assess the postoperative complications, pain, conversion rate and duration of hospital stay following LA in our surgical practice.

\section{Materials and methods}

Study population and Methods: This study was carried out in Surgery Unit 1 of BIRDEM General Hospital, Dhaka, Bangladesh from 30.09.14 to 30.09.16. All patients admitted at BIRDEM hospital with the diagnosis of acute appendicitis
(AA) were considered eligible and included in the study. But, those patients with congenital anomaly, morbid obesity and other systemic failure were excluded.

The laparoscopic technique was performed after a Hasson trocar was placed through the umbilical scar with the open technique [3,5]. The camera was introduced into the abdomen through this trocar, two more trocars were positioned. The first one $(5-\mathrm{mm})$ was placed in the midline just above the pubis and the second one $(10 \mathrm{~mm})$ in the left iliac fossa, in a point on the left-side perfectly symmetrical to the McBurney point. The appendicular artery was coagulated with a bipolar electrocautery. The procedure was completed by using two endoloops (ready-made or handmade) and the appendix extracted with an endobag. The patients were discharged after the passage of flatus.

The socio-demographic data and the post-surgical information (duration of pain, hospital stay, peroperative findings) were noted and presented. The assessment of pain was done as suggested by Dansie EJ and Turk DC [13]. The qualitative data were presented in percentages and quantitative in mean with standard deviation (SD).

\section{Results}

The age and sex distribution of the study population is presented in Table 1 which suggest that majority of the patients were female (55.3\%). Mean age of male and female patients were $21 \pm 1.4$ and $19 \pm 1.7$ years respectively (Table 1 ). Of the total 47 clinically diagnosed cases of acute appendicitis, $5(10.6 \%)$ were misdiagnosed as appendicitis and $2(4.3 \%)$ patients underwent

Table-1: Age and sex distribution of study population.

\begin{tabular}{lcccccc}
\hline \multirow{2}{*}{$\begin{array}{c}\text { Age in } \\
\text { years }\end{array}$} & \multicolumn{2}{c}{ Male } & \multicolumn{2}{c}{ Female } & \multicolumn{2}{c}{ total } \\
\cline { 2 - 7 } & $\mathbf{n}$ & $\boldsymbol{\%}$ & $\mathbf{n}$ & $\boldsymbol{\%}$ & $\mathbf{n}$ & $\%$ \\
\hline$<20$ & 07 & 14.9 & 09 & 19.1 & 16 & 34.0 \\
$20-30$ & 11 & 23.4 & 13 & 27.7 & 24 & 51.1 \\
$31-40$ & 03 & 6.9 & 04 & 8.5 & 07 & 14.9 \\
Total & 21 & 44.7 & 26 & 55.3 & 47 & 100 \\
\hline Mean age & \multicolumn{2}{c}{$21 \pm 1.4$} & \multicolumn{2}{c}{$19 \pm 1.7$} & \multicolumn{2}{c}{$20.0 \pm 1.6$} \\
$\pm S D(y r)$ & & & & & &
\end{tabular}

Note: SD: Standard deviation 
conversion to open surgery (OA), as required peroperatively, based on the laparoscopic findings. Those two were found to have other pathology that necessitated conversion to open appendectomy. One was suspected to be malignant though later proved otherwise and the other had extensive adhesion.

The result of postoperative assessment of pain is shown in Figure-1. It was found that the pain score of all cases was gradually reducing and fell below 2 or even less after 30 hours (pain scale: 0 to 10 , where 0 reflects no pain and 10 indicate severe intractable pain) [13].

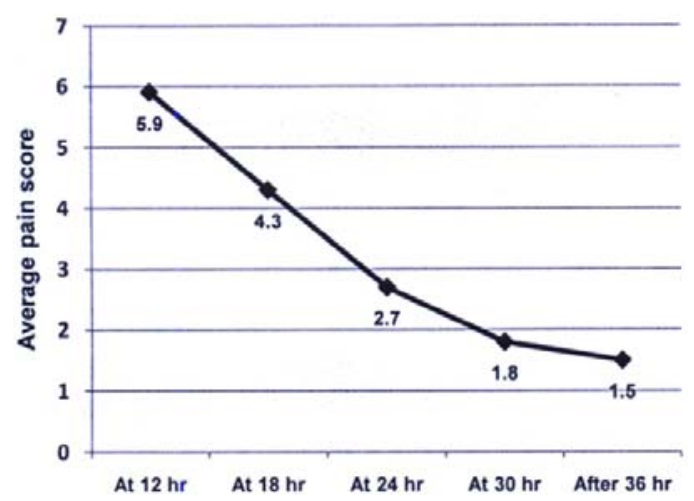

Fig.1: The assessment of post-laparoscopic pain with duration [13].

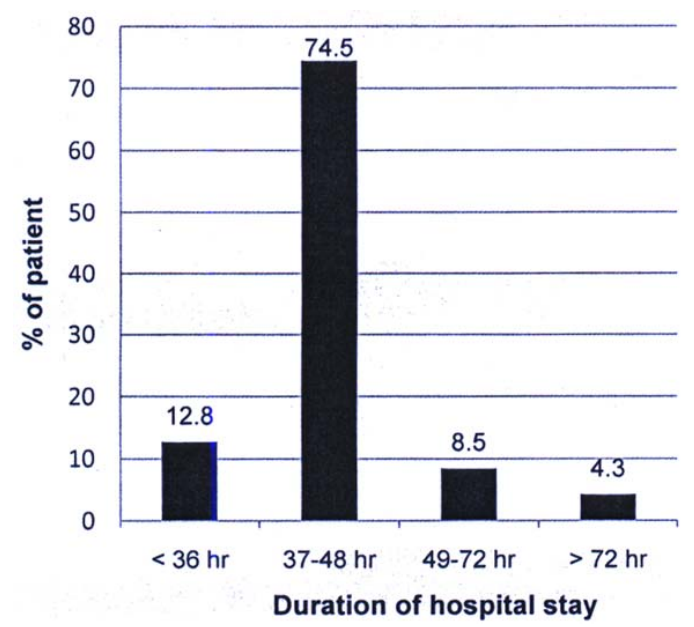

Fig.2: Average duration of hospital stay following laparoscopic appendectomy

Post-surgical complications were minimal. Port site bleeding was found only in $4.3 \%$ and port site infection was only $2.1 \%$. There were no other complications like visceral bleeding, subcutaneous emphysema and injury.

Post-surgical hospital stay was also very less. More than $80 \%$ patients were discharged from the hospital following laparoscopic appendectomy within 72 hours; whereas, only $4.3 \%$ patients required hospitalization after 72 hours for followup and management of bleeding (figure 2).

\section{Discussion}

Recent studies compared clinical outcomes of laparoscopic appendectomy (LA) versus open appendectomy (OA) [3-5,7]. Most studies opined in favor of LA $[1-3,4,5,7]$. In this study, we found female preponderance and younger age. This finding is consistent with other studies $[2,3,5]$. As for other reported studies this study findings are consistent with the past experience in other population with regards to post-operative outcomes $[8,10,11,13]$. For example, the study patients had less duration of pain and hospital stay thus reducing treatment cost. Obviously, these are very much consistent with other studies as mentioned earlier. Again, the incidence of per- and postoperative bleeding were also negligible $(<5 \%)$. The infection rate was also less $(<3 \%)$. However, these findings could have been better judged or compared if we could have a comparative group undergoing open appendectomy. This was an important limitation of the study.

\section{Conclusion}

Laparoscopic appendectomy (LA) was found relatively safe and resilient procedure. We had an additional benefit of LA. It revealed ten percent were misdiagnosed as having appendicitis. Though there was no comparative group, it was apparent that laparoscopic approach was proved to have reduced pain, less complication and shorter hospital stay thus reducing the treatment cost.

\section{Acknowledgements}

We are very much grateful to the physicians working at outpatient department and Emergency department of BIRDEM for referring the patients to the department of Surgery. We are indebted to the nursing and other supporting staff for assisting in supervision and follow-up of the study patients. 
Maitra TK et al.

\section{References}

1, Costa-Navarro D, Jiménez-Fuertes M, IllànRiquelme A. Laparoscoic appendectomy: quality care and cost-effectiveness for today's economy. World J Emerg Surg. 2013; 8(1): 1-5.

2. Editorial. A sound approach to the diagnosis of acute appendicitis. Lancet. 1987; 1: 198-200.

3. Horvath P, Lange J, Bachmann R, Struller F, Königsrainer A, Zdichavsky M. Comparison of clinical outcomes of laparoscopic versus open appendectomy for complicated appendicitis. Surg Endosc. 2016; doi: 10.1007/s00464-0164957-z.

4. Kehagias I, Karamanaks SN, Panagiotopoulos S, Panagopoulos K, Kalfarentzos F. Laparoscopic versus open appendectomy: which way to go? World J. Gastroenterol. 2008; 14: 4909-14.

5. Wullstein C, Barkhausen S, Gross E. Results of laparoscopic versus conventional appendectomy in complicated appendicitis. Dis Colon Rectum. 2001; 44:1700-5.

6. McBurney C. The incision made in the abdominal wall in cases of appendicitis, with a description of a new method of operating. Ann Surg. 1894; 20: 38.

7. Van LV, Jose MV. Laparoscopic Versus Conventional Appendectomy. Ann Surg. 1993; 218(5): 685-692.
8. Nana AM, Ouandji CN, Simoens C, Smets D, Mendes da Costa P. Laparoscopic appendectomies: results of a monocentric prospective and non-randomized study. Hepatogastroenterology. 2007; 54(76): 1146-1152.

9. Semm K. Endoscopic appendectomy. Endoscopy. 1983; 15: 59-64.

10. Long KH, Bannon MP, Zietlow SP, Helgeson ER, Harmsen WS, Smith CD, et al. A prospective randomized comparison of laparoscopic appendectomy with open appendectomy: clinical and economic analyses. Surgery. 2001; 129(4): 390-400.

11. Martin LC, Puente I, Sosa JL, Bassin A, Breslaw R, McKenney MG, Ginzburg E, Sleeman D. Open versus laparoscopic appendectomy. A prospective randomized. Ann Surg. 1995; 222(3): 256-262.

12. Guller LU, Hervey S, Purves H, Lawrence H. Laparoscopic versus open appendectomy: outcomes comparison based on a large administrative database. Ann Surg. 2004; 239(1): 43-52.

13. Dansie EJ, Turk DC. Assessment of patients with chronic pain. Br J Anaesth. 2013; 111: 19-25. 